\title{
Implementation of Tuberculosis and Human Immune-Deficiency Virus Programs Collaborative Services in Public-Private Mix Direct Observed Therapy Short Course Facilities in Addis Ababa, Ethiopia: Cross Sectional Facility Based Mixed Method
}

\author{
Lakew Huluka Bahiru1, Mesele Damte Argaw ${ }^{1 *}$, Maeza Demissie ${ }^{2}$ \\ ${ }^{1}$ Private Health Sector Program, Addis Ababa, Ethiopia \\ ${ }^{2}$ Addis Continental Institute of Public Health, Addis Ababa, Ethiopia \\ Email: lakewhuluka07@yahoo.com, "mdamte5@gmail.com, meazademissie@yahoo.com
}

Received 12 March 2016; accepted 10 May 2016; published 13 May 2016

Copyright (C) 2016 by authors and Scientific Research Publishing Inc.

This work is licensed under the Creative Commons Attribution International License (CC BY).

http://creativecommons.org/licenses/by/4.0/

(c) (i) Open Access

\section{Abstract}

Background: Ethiopia is one of the countries with the highest Human Immune-deficiency Virus (HIV) and Tuberculosis (TB) infection rates in the world. To improve TB/HIV Programs outcomes through Public Private Partnership Mix (PPM) approach was in place since 2006. But the status of its implementation has never been assessed. Methods: In this cross sectional study we employed mixed methods; we interviewed 272 tuberculosis patients, reviewed their records, and facilitated six in-depth interviews and four focus group discussions. The survey was conducted from January through March 2014 in Addis Ababa. Result: Among the interviewees 51.5\% were males and the mean age was $(32.7 \pm$ SD 12.4) years. PPM facilities were offering HIV counseling for all TB patients; whereas $87.5 \%$ of TB patients have received HIV testing services. The TB/HIV co-infection rate was $45.4 \%$. And only $72.2 \%$ TB/HIV patients were enrolled into chronic disease care services, 64.8\% were put on Cotrimoxazol Preventive Therapy (CPT) and $50 \%$ were put on standard highly active anti-retro viral therapy (HAART) services. All PPM facilities don't have IPT (Isoniazid Prophylaxis Therapy). The TB/HIV collaborative services strongly linked with the public health sector which was documented by developing inclusive work plan which create access to supplies and conducting joint supportive supervisions. However, the majorities of PPM facilities don't have Multi-Disciplinary Team and lacks some essential supplies. The predictor for uptake of CPT were:

How to cite this paper: Bahiru, L.H., et al. (2016) Implementation of Tuberculosis and Human Immune-Deficiency Virus Programs Collaborative Services in Public-Private Mix Direct Observed Therapy Short Course Facilities in Addis Ababa, Ethiopia: Cross Sectional Facility Based Mixed Method. Open Journal of Epidemiology, 6, 109-120. 
being females $\mathrm{TB}$ patients was $86 \%$ lower than their counter part males $(\mathrm{AOR}=0.14 ; 95 \% \mathrm{CI}=$ $0.04-0.92 \mathrm{P}=0.002$ ), patients who has attended their TB/HIV care at private for the profit facilities were $84 \%$ lower than those attend in private not for profit facilities $(\mathrm{AOR}=0.16 ; 95 \% \mathrm{CI}=$ $0.49-0.55, P=0.003$ ). Conclusions: The TB/HIV collaborative services at program level are stronger but only half of patients didn't get the comprehensive TB/HIV collaborative services to achieve recommended quality of care. Strengthening the services and ensuring the availability of essential supplies was highly recommended.

\section{Keywords}

Tuberculosis, Human Immune-Deficiency Virus, Implementation, Collaborative, Predictors, Public Private Mix, Ethiopia

\section{Introduction}

Tuberculosis (TB) is an airborne infectious disease cause by Mycobacterium tuberculosis, a rod-shaped bacillus called "acid fast" due to its staining characteristics in laboratory. The disease most commonly transmitted by inhalation of infected droplet nuclei when a person with an active TB infection in their lungs coughs or sneezes [1]-[3]. The most common method for diagnosing TB worldwide remains sputum smear microscopy (developed more than 100 years ago), in which bacteria are observed in sputum samples examined under a microscope [1] [3]. In addition, human immunodeficiency virus (HIV) is a virus that attacks the body's natural defense system. Without a strong immune system, the body has trouble fighting off disease. Both the virus and the infection it causes are called HIV [4].

World Health Organization (WHO) developed a strategic framework of programs collaboration to decrease the burden of Human Immune-deficiency Virus (HIV) related Tuberculosis (TB) [5]. Partners in Health (PIH) recommended the need for creating linkages with or between TB and HIV programs for better utilize resources, avoid missed opportunities and accelerate universal access to comprehensive TB and HIV prevention, treatment and care services in resource poor settings [6]. TB/HIV programs collaboration is endorsed by Ethiopian Federal Ministry of Health (EFMOH) to improve quality of care. The program integration is expected to impact on access for services, reduce burden of both diseases and prevention of disease transmission [1]. Studies indicate that Voluntary Counseling and Testing (VCT) for HIV can contribute for more coherent response for TB [7] [8].

According to the WHO global TB report of the year 2013, in the previous year there were estimated 8.6 million incidents TB cases. And out of these 1.1 million (13.0\%) were HIV positive. In the same year about $75.0 \%$ of the cases were reported from the Africa Region [9]. Ethiopia is one of the countries with the highest HIV and TB infection rates in the world [10]. The incidence of TB was estimated for the year 2010/2011 and it was reported as 156 and 240 per 100,000 populations for new smear positive pulmonary and all forms of TB respectively. The adult HIV prevalence rate for the same year was $1.4 \%$, and close to 720,000 people, among which 390,000 women and 180,000 children lives with HIV [11].

At the end of 2001 WHO evaluate its "ProTEST" (an acronym for Promotion of voluntary testing) initiative to the core intervention of TB case finding, Isoniazid Prophylaxis Therapy and comprehensive prevention of TB/HIV and care [7]. WHO recommended TB/HIV programs collaboration in high HIV prevalent and TB burdened sub-Saharan Countries [1] [9]. Ethiopia has exercised TB/HIV programs collaborative activities since 2004 [12]. In the following year, after taking the lesson from the pilot sites, the first TB/HIV collaborative implementation guidelines was indorsed by EFMOH and expansion of services were made in 450 out of 1526 public health facilities [13].

The TB/HIV programs collaborative approach aims to provide integrated and comprehensive tuberculosis, HIV prevention treatment and care service as close to the client as possible, maintaining existing tuberculosis and HIV program management structure [1]-[8]. The major activities suggested for the effective and efficient implementation of TB/HIV collaborative services includes joint planning, implementation, mentoring, coordination and evaluation of both programs. The strategy WHO encompasses intensified TB case finding from all people living with HIV to be regularly screened for TB during the initial presentation for HIV care and at every visit to a health facility or contact with a health-care worker afterwards [11]. And screening for TB is strongly 
recommended regardless of whether they have received or are receiving Isoniazid Preventive Therapy (IPT) or highly active antiretroviral treatment (HHART) [9] [10]. Moreover; eligible TB/HIV patient (CD4 < 350 cells/ $\mu \mathrm{L}$ ) should be put on Cotrimoxazol Preventive Therapy (CPT), and TB/HIV co-infected patients ought to link to chronic HIV care services [9] [10]. All TB patients should get HIV Counseling and Testing (HCT) services, which target to reduce risky sexual behavior, promotion of safe sex and treatment of sexually transmitted infections [7] [14].

Ethiopian Federal Ministry of Health (EFMOH) in 2006 adopted the WHO Stop TB strategy by engaging all health care providers in TB Control i.e. public, voluntary corporate and private providers through Public Private Mix (PPM) approaches [13]. TB/HIV collaborative services were among the key strategies clearly stated in the National Guidelines for clinical and programmatic management of TB/HIV in the country [3]. Nationally, in the development of partnerships for TB/HIV collaborative services major partners were engaged to enroll 90 private health facilities to provide HIV/AIDS, TB prevention and treatment services in Ethiopia [13].

A report of twenty nine PPM DOTS facilities in Addis Ababa revealed that $80 \%$ of Tuberculosis patient had received HIV test and the co-infection rate with TB was $23 \%$. But only $20 \%$ of HIV positive TB patients were enrolled on ART and no patients have got IPT [15]. Moreover; the private health facilities committed to share and shoulder social responsibilities by providing quality to the standard TB/HIV collaborative services through affordable cost [13]. There are no studies that have assessed the level of implementation of TB/HIV programs collaborative services in PPM-DOTS facilities in Ethiopia. Therefore, this study was designed to investigate the level of TB/HIV collaborative services implementation and factors associated with TB/HIV collaborative services utilization in the PPM-DOTS facilities in Addis Ababa, Ethiopia.

\section{Operational Definition}

Public Private Mix: a comprehensive approach to engage relevant health care providers through Public-Private (between the government TB program and the private sector) Public-Public (between the government TB program and other public sector care provider) an Private-Private (between civic society organizations or private hospitals and community based private providers) partnerships to deliver standardized, high quality TB care to all [1] [13]. Public Private Partnerships (PPPs): any explicit joint program or project involving public and private collaboration to provide services. These include contracting between the public sector (either governments or development agencies) and private providers to provide goods and services [13]. TB HIV Collaboration at Program Management level: TB/HIV collaborative services will be led by nationally established coordinating mechanism (at Federal, Region, Zone, THOs and Facility) level. The objective is to reduce burden of Tuberculosis and HIV. So as HIV prevention care and treatment should be a priority for tuberculosis control program; tuberculosis prevention and treatment should be priority concern for HIV prevention and control program. HIV Positive TB patients shall get Cotrimoxazol preventive Therapy (CPT) and HIV positive clients (without active TB shall get Isoniazid Preventive Therapy (IPT) and facilitate ART services [10].

\section{Methods and Materials}

\subsection{Study Setting and Sample}

Ethiopia is located in a tropical area which covers the latitude and longitude $8^{\circ} 00 \mathrm{~N}$ and $38^{\circ} 88 \mathrm{E}$ respectively [16]. Addis Ababa is the capital city of Ethiopia. It has ten sub cities and one hundred sixteen districts. There are 62 Public and 608 Private Health Facilities with high potential health services coverage [1]. The private health sector is growing up in provision of public health services through the established Public Private Mix Partnerships for TB and HIV services in the city. There are 47 and 29 TB/HIV management units in Public Health Facilities and Private Health Facilities respectively [15] [17]. According to the report of EFMOH for the year 2011/12, in Addis Ababa City there was 7105 TB case notified to the health bureau [17]. The contribution of the Private Health Facilities engaged in PPM DOTS Services was 1385 (19.5\%) [15] [17]. All public private partner facilities are expected to provide to the standard TB/HIV collaborative services for patients.

A cross sectional institutional based study was carried out using a mixed (Quantitative and Qualitative) methods. It was conducted using structured, semi structured and open ended questionnaires to study the level of implementation of TB/HIV collaborative services in the PPM-DOTS facilities. We selected all 27 medium and higher clinics with PPM DOTS services in Addis Ababa. The number of interviews and Focus Group discus- 
sions were determined based on saturation of data. Therefore, six key informants and four FGDs with thirty two discussants were selected though purposive sampling.

The sample size for interviewer administered questionnaire was calculated using single proportion as follow: The formula:

$$
n i=\frac{Z^{2} a / 2 p(1-p)}{d^{2}} \text { was employed [18]. }
$$

where ni is sample size, $\mathrm{P}$ is the proportion of TB/HIV patients who received CPT in the PPM-DOTS Facilities in Amhara Region and $d$ is the margin of error. The following assumptions were used. Since $\mathrm{P}$ is $39 \%(\mathrm{P}=0.39$, $\mathrm{q}=0.61$ (13). Allowing $5 \%$ for expected margin of error (d) and with $95 \%$ confidence level, and the required sample size ni is 366. With finite population correction formula: $n_{0}=[n i /(1+(n i / N))]$, where $N=1385$ (total number of tuberculosis patients who received TB/HIV collaborative services in PPM-DOTS facilities in Addis Ababa) this gives us $n_{0}$ is equal to 290 and $10 \%$ for non-response (refusal to be enrolled and drop outs) makes the sample size 319 [19].

\subsection{Data Collection Procedure}

The questionnaire was prepared first in English and then translated into Amharic. To maintain the consistency of the tool it was back translated to English by two different professionals. The interviewer administered structured questionnaire consists of the age, sex, educational level, monthly income, and permanent residents of the respondents. in addition, the tool address the knowledge, attitude and practices of TB/HIV patients towards the diseases and collaborative services. The semi structured data abstraction form enable the investigators to gather information on the classification, TB treatment Category, CD 4 cell counts, HIV test offered, test performed and results accepted by TB/HIV patients. Similarly, data on uptake of chronic care services were collected. The open ended in-depth interview and FGD facilitation guides were developed to capture the phenomena TB/HIV collaborative program services as experienced by the health workers and patients. In addition to this, the tool address factors influencing uptake of TB/HIV collaborative services.

The data collectors and their supervisors attended the necessary training on the objective of the study, data collection techniques, procedures and instruction to complete the questionnaires. The tools were pretested in public health facilities, which were not part of our study. After pretest the data collection tool was amended to accommodate essential data for the study. Four data collectors and two supervisors took the facilitation of collecting data from selected study subjects. The quantitative data were collected using interviewer administered structured questionnaires, and record reviews. While, the qualitative data collection were facilitated by the principal investigator accompanied by experienced public health professionals. The in depth interview was conducted by the experienced public Health Professionals. Both hand written note and tape recorder were employed to collect the qualitative data. Then it was transcribed, coded and thematically analyzed.

\subsection{Data Quality Control}

A two days long briefing and pretesting was arranged for data collectors and supervisors. Moreover, to maintain the quality of data the questionnaires were pre-tested in nearby public health facilities in Addis Ababa. The data collection tools were amended based on the finding of the pilot test. On daily bases supportive supervisions were conducted and immediate corrective action made as needed. Every questionnaire was checked for completeness before the interviewers acknowledge the patient for their time and contribution in the study. Similarly, supervisors provided feedbacks on the quality of the data on daily basis. In addition, filled questionnaires were cleaned and coded to enter into the computer by the data encoder.

The quality of the in depth interviews and focus group discussions were maintained by immediately transcribing the data and thematically analysis was made. The subsequent qualitative data collections were made after revising the tools based on the evidence from the preceding similar event.

\subsection{Data Processing and Analysis}

The quantitative data were checked for completeness and cleaned manually. The data were entered into Microsoft Office Excel 2010 version and export to Statistical Package for Social Sciences (SPSS IBM 20.0) [20]. First the descriptive findings were presented with tables and graphs. Cross tabulations were made in the determina- 
tion of Crude Odds Ratios, $\mathrm{p}$-values and $\mathrm{X}^{2}$. Statistical significance tests, the cut-off value set is $\mathrm{p}<0.05$ to claim statistical significant. To identify predictor factors related to the patients on uptake of CPT, uni-variable and multi-variable logistic regression analysis were employed. We reported the Adjusted Odds Ratio (AOR) with 95\% Confidence Interval (CI).

The tape recorded qualitative data were transcribed. Both the hand written notes and transcribed data were read and re-read by the investigators several times. Then, the researchers focused on level of implementation of TB/HIV programs and factors influencing uptake of services. The data patterns were identified, categorizedand coded. The major findings were thematically analyzed manually. The summary of the finding was used to explore new ideas and opinions of the participants. Finally, interpretations of information were made. And we used it to triangulate the findings of different data summary [21] [22].

\subsection{Ethical Clearance}

Ethical clearance was sought from Gondar University and Addis Continental Institute of Public Health Institutional Review Board (IRB). The standard consent form was adopted for this study [23]. Written permission was obtained from Addis Ababa City Administration Health Bureau, facility owners and individual participants. Participants were informed about the issue of confidentiality and that they had full right to refuse or discontinue participating in the research without any compromise in the relationship with the care of services they received in the private health facilities, hence, the study subjects participated voluntarily in to the study. The collected data were used only for study purpose. A code number was used to identify every participant and no names/ identifiers were used. Participants got adequate information on that all the data obtained were kept strictly confidential by using only code numbers and was stored in locked file cabinets, to be accessed only by the principal investigator, and destroyed immediately when the study is finalized.

\section{Result}

Out of the expected 319 participants 272 tuberculosis patients with a response rate of $85.5 \%$ were enrolled in this study. Almost half $51.5 \%$ of the study participants were males and the rest of the participants $48.5 \%$ were females. The mean $( \pm \mathrm{SD})$ age of the respondents was $32.72( \pm 12.43)$ years, and the median age was 35 years. The range of participant's age was 64 years (Maximum 82 to Minimum 18 years). Close to half of the respondents $50.7 \%$ were married, $34.9 \%$ were single and the rest $14.2 \%$ were either divorced or widowed or early to be engaged. Half of the respondents 50.4\% reported that their religions as Christian and followed by $29.4 \%$ Muslim. With regards to the educational background of the respondents: $7.7 \%$ were illiterate, $14.3 \%$ were able to read and write, one fifth of 19.5\% were achieved grade 4 to 8 , a little higher than one third $37.1 \%$ achieved grade 9 12 and one fifth $21.3 \%$ were completed a higher education with diploma and above. The two major ethnic categories for the respondents $36.4 \%$ and $31.3 \%$ were Amhara and Oromo, respectively. One fifth of the respondents $20.2 \%$ have reported they have a monthly income less or equal to 600 Ethiopian birr per month (Table 1).

TB/HIV patients were asked about their history of service utilization and $90.1 \%$ of tuberculosis patients have ever had received HIV counseling and testing (HCT) services. Almost half of the respondents (50.2\%) had learned their HIV test result earlier than diagnosed for TB, while a little below half of them had HCT service during the course of TB treatment. The main reason reported for not accepting the offered HIV testing and counseling services were $25.9 \%$ fear of accepting positive HIV test result, $25.9 \%$ fear of stigma and discrimination and 22.2\% patient felt they don't have risk of acquiring HIV infection (Table 2). This finding was supported by the result of FGD: three FGD discussants preferred the PPM DOTS facilities for their health problem, since the facilities are locate close to their home hence, it shorten the time dedicated during taking daily treatment services. However, due to incomplete services in a single facility they have fear of disclosure of their HIV status.

A 35 year old TB/HIV patient explained the situation by saying:

"When Health Workers gave me prescription to buy CPT from drug outlets, I should buy 12 strips for one month consumption. But I had fear of the stigma associated with disclosing my HIV status."

Both males and females FGDs discussants believe the initiation of TB/HIV programs collaborative services in private health facilities improve access to services and address the treatment complaints of patients. Moreover, all discussants agree the number of TB patients in private facilities is manageable and it didn't take up much of their time every day.

A 37 years old housewife stated the situation as follow: 
Table 1. Socio-demographic characteristics of respondents, in PPM/DOTS sites in Addis Ababa, March 2014 (n = 272).

\begin{tabular}{|c|c|c|}
\hline Characteristics & Frequency & Percent \\
\hline \multicolumn{3}{|l|}{ Sex } \\
\hline Male & 140 & $51.5 \%$ \\
\hline Female & 132 & $48.5 \%$ \\
\hline \multicolumn{3}{|l|}{ Age groups in year } \\
\hline $15-19$ & 24 & $8.8 \%$ \\
\hline $20-24$ & 45 & $16.5 \%$ \\
\hline $25-29$ & 60 & $22.1 \%$ \\
\hline $30-34$ & 48 & $17.6 \%$ \\
\hline $35-39$ & 31 & $11.4 \%$ \\
\hline $40-44$ & 24 & $8.8 \%$ \\
\hline $45-49$ & 12 & $4.4 \%$ \\
\hline $50+$ & 28 & $10.3 \%$ \\
\hline \multicolumn{3}{|l|}{ Educational status } \\
\hline Illiterate & 21 & $7.7 \%$ \\
\hline Read and write & 39 & $14.3 \%$ \\
\hline Grade 4 - 8 & 53 & $19.5 \%$ \\
\hline Grade 9 - 12 & 101 & $37.1 \%$ \\
\hline Diploma + & 58 & $21.3 \%$ \\
\hline \multicolumn{3}{|l|}{ Religion } \\
\hline Orthodox & 137 & $50.4 \%$ \\
\hline Muslim & 80 & $29.4 \%$ \\
\hline Protestant & 47 & $17.3 \%$ \\
\hline Catholic & 8 & $2.9 \%$ \\
\hline \multicolumn{3}{|l|}{ Ethnicity } \\
\hline Amhara & 99 & $36.4 \%$ \\
\hline Oromo & 85 & $31.3 \%$ \\
\hline Guragie & 59 & $21.7 \%$ \\
\hline Tigrie & 27 & $9.9 \%$ \\
\hline Other & 2 & $0.7 \%$ \\
\hline \multicolumn{3}{|l|}{ Marital status } \\
\hline Married & 138 & $50.7 \%$ \\
\hline Single & 95 & $34.9 \%$ \\
\hline Divorced & 21 & $7.7 \%$ \\
\hline Widowed & 11 & $4.0 \%$ \\
\hline Other & 7 & $2.5 \%$ \\
\hline \multicolumn{3}{|l|}{ Monthly income\# } \\
\hline$\leq 600$ & 55 & $20.2 \%$ \\
\hline $601-1200$ & 104 & $38.3 \%$ \\
\hline$\geq 1201$ & 113 & $41.5 \%$ \\
\hline
\end{tabular}

NB: ${ }^{\#-1 U S D}=19.00$ ET Birr. 
Table 2. Prevalence HIV testing, barriers and place of service uptake among Tuberculosis in PPM/DOTS facilities in Addis Ababa, March 2014.

\begin{tabular}{|c|c|c|}
\hline TB, HIV/AIDS related questions & Frequency & Per-cent \\
\hline \multicolumn{3}{|l|}{ Ever tested $(n=272)$} \\
\hline Yes & 238 & $87.5 \%$ \\
\hline No & 34 & $12.5 \%$ \\
\hline \multicolumn{3}{|l|}{ The reason for HIV testing \# $(\mathrm{n}=238$ ) } \\
\hline Voluntary testing (self-request) & 127 & $53.3 \%$ \\
\hline Test and Counseling initiated by HW & 106 & $44.5 \%$ \\
\hline Pre-marriage & 5 & $2.2 \%$ \\
\hline \multicolumn{3}{|l|}{ When did you get tested for HIV $(n=238)$} \\
\hline Before TB diagnosis & 123 & $51.7 \%$ \\
\hline During TB treatment & 102 & $42.9 \%$ \\
\hline Don’t know & 13 & $5.4 \%$ \\
\hline \multicolumn{3}{|l|}{ Utilized HIV testing centers $(n=245)$} \\
\hline PPM DOTS/in TB treatment center & 122 & $51.2 \%$ \\
\hline Free standing VCT center & 73 & $30.6 \%$ \\
\hline Other than PPM-DOTS facility & 42 & $17.6 \%$ \\
\hline Don’t know & 2 & $0.8 \%$ \\
\hline \multicolumn{3}{|l|}{ Testing Barriers \# $(\mathrm{n}=34)$} \\
\hline Fear of accepting positive test & 10 & $29.4 \%$ \\
\hline Fear of partners reaction & 8 & $23.5 \%$ \\
\hline I don't have risk of HIV & 7 & $20.5 \%$ \\
\hline Fear of stigma and discrimination & 6 & $17.6 \%$ \\
\hline Partner tested & 2 & $5.8 \%$ \\
\hline No benefit of HIV Testing & 1 & $2.9 \%$ \\
\hline
\end{tabular}

“The PPM-DOTS facility where I collect my drugs is very close to my house; furthermore, the health workers are very concerned about my treatment. If I don't visit on time they check me through phone whether I get trouble or not."

The patient information about TB/HIV services uptakes was abstracted from TB unit register. The majority 93.0\% was register as new TB patient and all 100.0\% had offered Provider Initiated HIV Testing and Counseling (PITC) services. However, 87.5\% accepted their test result. The TB/HIV co-infection rate was 45.5\%. And 72.2.0\% was enrolled in chronic HIV care service. CD4 tests were done for $79.6 \%$ of eligible patients. Among TB/HIV patients who were eligible for CPT (CD4 < 350 cells $/ \mu L$ ) $64.8 \%$ were on treatment and among HIV positive TB patients only half 50.0\% were started HAART (Table 3 ).

The majority (5/6) of FGD discussants of the health workers team and key informants reported that they want to provide comprehensive and high quality TB/HIV care for patients. Nonetheless, interruption of laboratory supplies and lack of access to all drugs recommended for opportunistic infection (OI) makes their service incomplete.

One of the 28 years old Health Officer described the poor quality of care due to drug interruption by saying:

“I want to provide a complete care for my patients but sometimes I don't have all essential supplies. I used to offer PITC services for all TB patients. In addition for clients with HIV positive result; I used to screen for presence of TB infection. Despite all the effort I made, I can't initiate IPT for a HIV positive patient with presumed negative TB diagnosis.”

A medical director and clinician in one of PPM-DOTS facilities mentioned the interruption of supplies of anti TB drugs as one of the major challenges to maintain the desired quality of services by saying:

"Six month ago I had a critical shortage of anti TB drug (especially Ethambutol) so I was not able to treat 
Table 3. Classification of TB patients and TB/HIV collaborative service uptake in PPM/DOTS sites in Addis Ababa, Ethiopia, March 2014.

\begin{tabular}{|c|c|c|}
\hline TB, HIV/AIDS related questions & Frequency & Per-cent \\
\hline \multicolumn{3}{|l|}{ Classification $(\mathrm{n}=272)$} \\
\hline Smear Negative PTB & 109 & $40.1 \%$ \\
\hline Smear Positive PTB & 88 & $32.4 \%$ \\
\hline ЕРТВ & 75 & $27.6 \%$ \\
\hline \multicolumn{3}{|l|}{ TB Treatment Category } \\
\hline New & 253 & $94.1 \%$ \\
\hline Relapse & 11 & $4.0 \%$ \\
\hline Transfer In & 3 & $1.1 \%$ \\
\hline Other & 3 & $1.1 \%$ \\
\hline Defaulter & 2 & $0.7 \%$ \\
\hline \multicolumn{3}{|l|}{ HIV test offered } \\
\hline Yes & 272 & $100.0 \%$ \\
\hline \multicolumn{3}{|l|}{ HIV test Performed } \\
\hline Yes & 238 & $87.5 \%$ \\
\hline No & 34 & $12.5 \%$ \\
\hline \multicolumn{3}{|l|}{ HIV test Result } \\
\hline Positive & 108 & $45.4 \%$ \\
\hline Negative & 130 & $54.6 \%$ \\
\hline \multicolumn{3}{|l|}{ CD4 Count } \\
\hline Yes & 86 & $79.6 \%$ \\
\hline No & 22 & $20.4 \%$ \\
\hline \multicolumn{3}{|l|}{ Enrolled on Chronic HIV care } \\
\hline Yes & 78 & $72.2 \%$ \\
\hline No & 30 & $27.8 \%$ \\
\hline \multicolumn{3}{|l|}{ On CPT } \\
\hline Yes & 70 & $64.8 \%$ \\
\hline No & 38 & $35.2 \%$ \\
\hline \multicolumn{3}{|l|}{ On HAART } \\
\hline Yes & 54 & $50.0 \%$ \\
\hline No & 54 & $50.0 \%$ \\
\hline
\end{tabular}

patients categorized as relapse cases.”

According to the response of the key informant, the level of implementation of TB/HIV collaborative services at program level seems quite good. The EFMOH endorsed PPM as one of the strategies in the national effort to control TB/HIV infections. Furthermore, the role and contribution PPM facilities were considered in the planning, implementing, budgeting, monitoring and evaluation of TB/HIV programs. For instance, Addis Ababa City Government Health Bureau and all sub cities arrange catchment meetings. All PPM DOTS facilities were among active participants of the meetings: discuss technical updates, opportunities, challenges, referral linkage and other programmatic issues. On top of this, private health facilities received clinical trainings, seminars, coaching and mentorship services from the RHBs and its structure. However, 5 (18.5\%) of PPM facilities established Multi-Disciplinary Team (MDT) which leads both TB/HIV Programs. TB and PITC related services are well integrated at facility level; but all private for profit PPM DOTS facilities couldn't provide chronic HIV/AIDS care services. They are limited only to providing referral services and prescribing drugs for opportunistic infections (OIs). 


\section{Factors Affecting Uptake of CPT}

This study assessed factors associated with uptake CPT. A logistic regression model was used to examine factors associated with uptake of CPT as dependent variable. In the bivariate logistic regression analysis, uptake of CPT was found statistically significant $(\mathrm{p}<0.05)$ relationship with sex $(\mathrm{P}=0.03)$, Patients who has income less than 600.00 ET birr 5.36 time didn't take CPT than their counter part patients with income greater or equal to 1201.00 Et birr (COR $\left.=5.36 ; 95 \% \mathrm{CI}=1.75-16.40, \mathrm{x}^{2}=9.28, \mathrm{P}=0.003\right)$. Whereas the uptake of CPT was not found statistically significant with age of patients less or equal to 35 years $(\mathrm{p}=0.28)$, income 601 to $1200 \mathrm{ET}$ birr $(p=0.27)$ education level below grade $4(p=0.30)$, grade $4-12(p=0.05)$ and attending TB/HIV care services in Private not for the profit facility $(\mathrm{p}=0.06)$ (Table 4).

The socio -demographic factors (sex, age, income, education) and the type of private facility adjusting as independent variables, against the dependent variable uptake of CPT were tested for any significant relationships. Being male TB/HIV patients 2.4 time took CPT than being female patient $(\mathrm{AOR}=0.14 ; 95 \% \mathrm{CI}=0.04-0.92$; $\mathrm{x}^{2}=4.77 \mathrm{P} 0=0.002$ ), Patients who has attended their TB/HIV Care services at private not for the profit facilities were 2.35 time more likely took CPT than those attend in private for profit facilities $(\mathrm{AOR}=0.16 ; 95 \% \mathrm{CI}=$ $0.49-0.55 ; \mathrm{x}^{2}=2.35, \mathrm{P}=0.003$ ) (Table 5).

\section{Discussions}

We conducted a facility based cross sectional study to determine the level of implementation of TB/HIV programs collaborative services in Addis Ababa, Ethiopia. Out of 29 PPM DOTS facilities 27 were volunteered to take parts. In these selected facilities 272 (85.2\%) of TB/HIV patients were enrolled. In addition, qualitative data were collected from six key informants and 32 FGD discussants. The implementations of TB/HIV collaborative services at programs level do have strength which is demonstrated in planning, implementing, budgeting, and monitoring and evaluation activities. But TB/HIV collaborative services at facility level is strong through provision of selected services, however, there is a limitation on leading the TB/HIV programs activities that is 5 (18.5\%) has established Multi-Disciplinary Team (MDT) to oversee the programs. The result of TB/HIV programs collaborative services includes improving access to diagnosis and treatment, demonstrate quality of care to the standard, and achieved targeted treatment outcomes.

Table 4. Uni-variable analysis of factors affecting uptake of Cotrimoxazol Prophylaxis Therapy in PPM-DOTS facility, Addis Ababa, Ethiopia, March 2014.

\begin{tabular}{|c|c|c|c|c|c|c|}
\hline \multirow{2}{*}{ Characteristics } & \multirow{2}{*}{ Category } & \multicolumn{2}{|c|}{ On CPT } & \multirow{2}{*}{ Crude OR } & \multirow{2}{*}{$95 \%$ CI } & \multirow{2}{*}{ P-value } \\
\hline & & Yes (\%) & No (\%) & & & \\
\hline \multicolumn{7}{|l|}{ Sex } \\
\hline & Male & 43 (74.1\%) & 15 (25.9\%) & 0.41 & $(0.18,0.92)$ & 0.03 \\
\hline & Female & 27 (54.0\%) & $23(46.0 \%)$ & 1 & -- & \\
\hline \multicolumn{7}{|l|}{ Age } \\
\hline & $\leq 35$ years & 46 (68.7\%) & 21 (31.3\%) & 0.65 & $(0.28,1.45)$ & 0.28 \\
\hline & $\geq 36$ Years & 24 (58.5\%) & 17 (41.5\%) & 1 & -- & \\
\hline \multicolumn{7}{|l|}{ Income } \\
\hline & $\leq 600$ ET birr & 9 (39.1\%) & 14 (60.9\%) & 5.36 & $(1.75,16.40)$ & 0.003 \\
\hline & 601 - 1200 ET birr & 30 (66.7\%) & 15 (33.3\%) & 1.72 & $(0.65,4.35)$ & 0.27 \\
\hline & $\geq 1201$ ET birr & 31 (77.5\%) & 9 (22.5\%) & 1 & -- & \\
\hline \multicolumn{7}{|l|}{ Education } \\
\hline & Below grade 4 & $14(66.6 \%)$ & 7 (33.3\%) & 2 & $(0.52,7.60)$ & 0.3 \\
\hline & Grade 4 - 12 & $3(58.0 \%)$ & 26 (41.9\%) & 2.8 & $(0.96,8.60)$ & 0.056 \\
\hline & Diploma plus & 20 (80.0\%) & $5(20 \%)$ & 1 & -- & \\
\hline \multicolumn{7}{|l|}{ Type of facility } \\
\hline & Private not for Profit & 27 (77.1\%) & 8 (22.9\%) & 0.42 & $(0.17,1.06)$ & 0.06 \\
\hline & Private for profit & 43 (61.4\%) & 30 (38.6\%) & 1 & -- & \\
\hline
\end{tabular}


Table 5. Multivariable analysis of factors affecting uptake of Cotrimoxazol Prophylaxis Therapy in PPM-DOTS facility, Addis Ababa, Ethiopia, March 2014 G.C.

\begin{tabular}{|c|c|c|c|c|c|c|c|}
\hline \multirow{2}{*}{ Characteristics } & \multirow{2}{*}{ Category } & On CPT & \multirow{2}{*}{$\begin{array}{c}\text { Crude } \\
\text { OR }\end{array}$} & \multirow{2}{*}{$95 \%$ CI } & \multirow{2}{*}{ AOR } & \multirow{2}{*}{$95 \%$ CI } & \multirow{2}{*}{ P-value } \\
\hline & & Yes (\%) & & & & & \\
\hline \multicolumn{8}{|l|}{ Sex } \\
\hline & Male & $43(74.1 \%)$ & 0.41 & $(0.18,0.92)$ & 0.14 & $(0.04,0.92)$ & 0.002 \\
\hline & Female & 27 (54.0\%) & 1 & -- & 1 & -- & \\
\hline \multicolumn{8}{|l|}{ Age } \\
\hline & $\leq 35$ years & 46 (68.7\%) & 0.65 & $(0.28,1.45)$ & 0.24 & $(0.07,0.79)$ & 0.02 \\
\hline & $\geq 36$ Years & 24 (58.5\%) & 1 & -- & 1 & -- & \\
\hline \multicolumn{8}{|l|}{ Income } \\
\hline & $\leq 600$ ET birr & $9(39.1 \%)$ & 5.36 & $(1.75,16.40)$ & 1.57 & $(0.39,6.38)$ & 0.52 \\
\hline & 601 - 1200 ET birr & 30 (66.7\%) & 1.72 & $(0.65,4.35)$ & 0.28 & $(0.06,1.24)$ & 0.09 \\
\hline & $\geq 1201$ ET birr & 31 (77.5\%) & 1 & -- & 1 & -- & \\
\hline \multicolumn{8}{|l|}{ Education } \\
\hline & Below grade 4 & $14(66.6 \%)$ & 2 & $(0.52,7.60)$ & 1.53 & $(0.30,7.78)$ & 0.6 \\
\hline & Grade 4 - 12 & $3(58.0 \%)$ & 2.8 & $(0.96,8.60)$ & 3.48 & $(0.88,13.78)$ & 0.07 \\
\hline & Diploma plus & $20(80.0 \%)$ & 1 & -- & 1 & -- & \\
\hline \multicolumn{8}{|l|}{ Type of facility } \\
\hline & Private not for Profit & 27 (77.1\%) & 0.42 & $(0.17,1.06)$ & 0.16 & $(0.49,0.55)$ & 0.003 \\
\hline & Private for profit & 43 (61.4\%) & 1 & -- & 1 & -- & \\
\hline
\end{tabular}

In this study we found that almost all (97.8\%) tuberculosis patient have heard about the presence of Provider Initiated HIV testing and counseling services in PPM facilities. This finding was a little higher than finding reported 77.7\% from a study conducted in PPM DOTS facilities in Addis Ababa [24]. The record reviewed for all 272 patients documented as Health Workers have offered PITC services to all TB patients and $87.5 \%$ have accepted HIV counseling and testing services. This finding was in line with $76 \%$ of TB patients which were offered and $90.0 \%$ accepted the test result in Rwanda [8]. However, the finding was much higher than $71 \%$ of TB patients were tested for HIV in Amhara region in PPM-DOTS facilities [25]. In this study we found TB HIV co-infection rate of $45.5 \%$, the finding was in line with $49.0 \%$ in Rwanda [8] but much higher rate of $33.5 \%$ which was reported in Felegehiwot Hospital of Amhara Region of Ethiopia [26]. This high prevalence could be occurred due to only five of private not for the profit facilities provide chronic HIV care services and three facilities served only People Living with HIV and their family members.

Out of the eligible TB/HIV patients uptake of CPT was $64.8 \%$. The finding was much lower than the report of Kassa et al 80.0\% linked for CPT in public health facility in Addis Ababa [12]. In other hand, the result of this study was much higher than 39\% in PPM DOTS facilities in West Amhara [25]. The difference could be due to that $18 \%$ of our study facilities are private not for profit so they have access to the public drugs including drugs for opportunistic infection. The presence of freely distributed HIV related opportunistic Infection (OI) drugs might improve uptake of services. And only $50 \%$ of TB/HIV patient were put on HAART. This finding was much higher than the report of Asefa 30\% TB/HIV co-infected patients are on ART in west Amhara PPM-DOTs facilities [25]. This finding would be explained by the difference on the number of ART sites. Since, among PPM facilities only private hospitals and private not for profit facilities have the chronic HIV care services. In addition to this, interruption of essential supplies compromised the level of implementation of TB/HIV programs collaborative services in selected PPM facilities.

The study documented the presence of strong TB/HIV Programs collaboration. But only one fifth of PPM facilities established MDT. Some of the factor identified to improve uptake of CPT by TB/HIV patients includes income, age, gender and type of health facilities. The first bivariate regression model pointed out that patients who received monthly income less or equal to $600 \mathrm{ET}$ birr were 5.3 time decline to take $\mathrm{CPT}(\mathrm{P} \leq 0.003)$ than those who have income greater or equal to 1201.00 Et birr. Through this association was not significantly associated in the 
result of multiple logistic regressions. But the qualitative data clearly indicated that patient may not want to disclose their HIV status through buying one hundred twenty tablets of cotrimoxazol for one monthconsumption.

The second factor identified was age of patients. TB/HIV patients who are less or equal to 35years took CPT than patients age greater or equal to 36 year $\mathrm{P}=002$. And male took CPT than females $\mathrm{P}=0.002$. This could be due to that the younger group and being male can have a higher income than being older patients and female. Patients who follow their TB/HIV treatment and collaborative services in private not for profit took much better than those who follow their care in private for profit facilities $(\mathrm{P}=0.003)$. This finding was in line with other studies where patient get drugs for opportunistic infections for free of charge took up $81 \%$ - 90\% in Oromia and Addis Ababa [12] [27].

The third factor identified was interruption of supplies and the partnerships in place in the form of PPM have limitations to provide complete and comprehensive HIV services for patients. This finding was in line with the report of the in-depth interviews and FGDs, which describe interruption of supply as a major challenge for quality of TB/HIV program collaborative services.

\section{Limitation}

The study does have some limitations since the study was conducted in PPM DOTS facilities, HIV Positive patients who are presumptively free of TB couldn't be the part of the study. Two private facilities were not voluntary to be the part of this study; hence the number of participants allocated in these facilities couldn't be the part of the study.

\section{Conclusion}

The TB/HIV programs collaborative service implementations at a higher level have strength on planning, organizing leading, implementing, monitoring and evaluation of every activity. But the facility level of implementation is not strong enough to lead and manage through MDT. The TB/HIV collaborative services is found strong in implementing selected services which include offering PITC and screening HIV positive patient for TB. However, $50.0 \%$ of TB/HIV patients were on HHART, $64.8 \%$ of illegible patients were on CPT and $72.2 \%$ were enrolled at chronic care services. Patients received TB/HIV services in private not for profit significantly took CPT than their counter parts who received the service in private not for profit facilities. Being male and age younger than 35 years old were statistically significant association with taking CPT than being female and age older than 36 years. The TB/HIV collaborative services are challenged by interruption of essential supplies. Therefore, strengthening the services and ensuring the availability of essential supplies were highly recommended.

\section{Acknowledgements}

The authors would like to express their gratitude to Gondar University and Addis Continental Institute of Public Health for approving this research. We are indebted to all data collectors and supervisors for their dedication and effort invested during the data collection process. We are obliged to thank all in Private health facilities owners, managers and patients who shared us their opinion and spend their invaluable time through completing the questionnaire.

\section{Competing Interest}

The authors declare that they have no competing interest.

\section{Authors' Contributions}

The authors' responsible were as follow: LHB, MDA \& MD: designed the research. LHB supervised the data collection and ensure the quality of collected data. LHB, MDA \& MD analyzed, interpreted the findings and drafted the manuscript. MDA the corresponding author submitted the paper for publication. All authors reviewed the manuscript and approved the final version.

\section{References}

[1] Federal Ministry of Health of Ethiopia (FMOH) (2013) Guidelines for Clinical and Programmatic Management TB, 
TB/HIV and Leprosy in Ethiopia. FMOH, Addis Ababa.

[2] Daniel, T.M. (2006) The History of Tuberculosis. Respiratory Medicine, 100, 1862-1870. http://dx.doi.org/10.1016/j.rmed.2006.08.006

[3] World Health Organization (WHO) (2015) Global Tuberculosis Report 2015. WHO, Geneva.

[4] WebMD (2016) HIV Topic Overview. http://www.webmd.com/hiv-aids/tc/human-immunodeficiency-virus-hiv-infection-topic-overview

[5] Maher, D., Floyd, K. and Raviglione, M. (2002) Strategic Framework to Decrease the Burden of TB/HIV. World Health Organization, Geneva, WHO Document WHO/CDS/TB/2002.296.

[6] Mukherjee, J.S. and Yang, A. (2008) The PIH Guide to the Community-Based Treatment of HIV in Resource Poor Setting. 2nd Edition, Partners in Health, Boston.

[7] Godfrey-Faussett, P., Maher, D., Mukadi, Y.D., Nunn, P., Perriëns, J. and Raviglione, M. (2002) How Human Immunodeficiency virus Voluntary Testing Can Contribute to Tuberculosis Control. Bulletin of the World Health Organization, 80, 939-945.

[8] Pevzner, E.S., Vandebriel, G., Lowrance, D.W., Gasana, M. and Finlay, A. (2011) Evaluation of the Rapid Scale-Up of Collaborative TB/HIV Activities in TB Facilities in Rwanda, 2005-2009. BMC Public Health, 11, 550. http://dx.doi.org/10.1186/1471-2458-11-550

[9] World Health Organization (WHO) (2013) Global Tuberculosis Report 2013. World Health Organization, Geneva.

[10] Federal Ministry of Health of Ethiopia (FMOH) (2007) Implementation Guidelines for TB/HIV Collaborative Activities in Ethiopia 2007. FMOH, Addis Ababa.

[11] United Nations Children Fund (UNICEF) (2013) Ethiopia Statistics. http://www.unicef.org/infobycountry/ethiopia_statistics.html

[12] Kassa, A., Jerene, D., Assefa, Y., Teka, A., Aseffa, A. and Deribew, A. (2012) Evaluation of Collaborative TB/HIV Activities in a General Hospital in Addis Ababa, Ethiopia. BMC Research Notes, 5, 67. http://dx.doi.org/10.1186/1756-0500-5-67

[13] Federal Ministry of Health of Ethiopia (FMOH) (2012) Public Private Mix Direct Observed Treatment Short Course Implementation Guidelines. 2nd Edition, FMOH, Addis Ababa.

[14] World Health Organization (2012) Policy on Collaborative TB/HIV Activities: Guidelines for National Programs and Other Stakeholders. WHO, Geneva.

[15] Private Health Sector Program (PHSP) Program Performance Report of Year 2012. PHSP, Addis Ababa.

[16] Map of the World (2015). http://www.mapsofworld.com/lat_long/ethiopia-lat-long.html

[17] Federal Ministry of Health of Ethiopia (FMOH) (2012) Annual Program Performance Report of Ethiopia for the Year 2011/2012. FMOH, Addis Ababa.

[18] Daniel, W. (1987) Biostatistics: A Foundation for Analysis in the Health Sciences. 4th Edition, John Wiley \& Sons Inc., New York.

[19] Pagano, M. and Gauvereau, K. (2000) Principles of Biostatics. 2nd Edition, Duxbury, Pacific Grove.

[20] SPSS, I. (2011) IBM SPSS Statistics Base 20. SPSS Inc., Chicago.

[21] Taylor-Powell, E. and Renner, M. (2003) Analyzing Qualitative Data.

[22] Pope, C., Ziebland, S. and Mays, N. (2000) Analysing Qualitative Data. BMJ, 320, 114-116. http://dx.doi.org/10.1136/bmj.320.7227.114

[23] ESTC (2005) Health Research Ethics. The Health Development of Ethiopian Science and Technology Commission in Collaboration with the Ethiopian Public Health Association and Regional Health Bureaus, Addis Ababa.

[24] Gebrekidan, G., Tesfaye, G., Hambisa, M.T. and Deyessa, N. (2014) Quality of Tuberculosis Care in Private Health Facilities of Addis Ababa, Ethiopia. Tuberculosis Research and Treatment. http://dx.doi.org/10.1155/2014/720432

[25] Assefa, M. (2013) Human Immuno-Deficiency Virus Status and Treatment Outcome of Tuberculosis Patients in Private Health Facilities in Bahir Dar City. 19th Conference of the International Union against Tuberculosis and Lung disease (The Union), MOH, Rwanda, Kigali Serena Hotel, 20-22 June 2013.

[26] Bezabih, B., Demilew, B., Andargie, N., Wondale, M., Mohammed, Z. and Amare, A. (2013) Assessment of Tuberculosis and HIV Co-Infection among Patients Attending TB Clinic in Felege Hiwot Hospital, Bahir Dar, North West Ethiopia. 8th Annual Conference of TB Research, FMOH, Addis Ababa, 21-23 March 2013.

[27] Alemu, A.W. and Sebastian, M.S. (2010) Determinants of Survival in Adult HIV Patients on Antiretroviral Therapy in Oromiyaa, Ethiopia. Global Health Action, 2010, 3. http://dx.doi.org/10.3402/gha.v3i0.5398 